\title{
Review of the State of Art of Tunable Impulse Ultra-Wideband Technology as Integrator for Wireless Sensing and Identifications Short-Range Networks
}

\author{
Mohammed Seed Jawad, Widad Ismail, Ayman Hajjawi, Othman Abdul Rani, \\ Abadal-Salam T. Hussain, Azahari Saleh \\ Faculty of Electronics and Computer Engineering (FKEKK), Univeristi Teknikal Malaysia Melaka (UTeM), Hang \\ Tuah Jaya, Durrian Tunggal, Melaka, Malaysia \\ Email: saeed@utem.edu.my, eewidad@usm.my, ayman 2747@yahoo.com, rani@utem.edu.my, \\ abadal@unimap.edu.my, azahari@utem.edu.my
}

Received 4 June 2014; revised 4 July 2014; accepted 5 August 2014

Copyright (C) 2014 by authors and Scientific Research Publishing Inc.

This work is licensed under the Creative Commons Attribution International License (CC BY). http://creativecommons.org/licenses/by/4.0/

(c) (i) Open Access

\begin{abstract}
Impulse based Ultra wideband technology has been the motivation of many recent researches with the potential of many applications to be researched. The uniqueness of the physical characteristics of the generated signal combined with the high flexibility of for different data rates at the physical layer design level have been addressed in considerable number of researches recently. This paper presents in depth reviews of the different concepts of tunable impulse based ultra wideband from the different researchers views. Research proposals of Cross layer architectures as PHY-MAC aware Impulse based ultra wideband solutions, link-budget communication design with performance evaluations in different test beds implementations are investigated in this paper. Such in-depth review can help researchers in this field to have better understanding of the different possibilities of designing new impulse-based ultra wideband solutions for future potential communication scenarios. Special focus on utilizing the advantage of impulse-based ultra wideband signal design flexibility as integrator for different short to medium wireless infrastructures mainly sharing common design constraints and requirements. Finding remarks from reviewing nearest-field literature combined with researches benchmarking to inspire researches proposal for this topic.
\end{abstract}

\section{Keywords}

IR-UWB, Tunable UWB, Cross-Layer Design, OFDM, UWB-WSN, UWB-RFID

How to cite this paper: Jawad, M.S., Ismail, W., Hajjawi, A., Rani, O.A., Hussain, A.-S.T. and Saleh, A. (2014) Review of the State of Art of Tunable Impulse Ultra-Wideband Technology as Integrator for Wireless Sensing and Identifications Short-Range Networks. Wireless Sensor Network, 6, 137-156. http://dx.doi.org/10.4236/wsn.2014.68015 


\section{Introduction}

Reviews in this paper begin with the latest definition of impulse-based UWB technology and its potential applications. The review includes the latest studies on short-ranges wireless infrastructures that can be combined for enhanced functionalities especially for wireless sensing and identifications. Also, exploring Impulse based UWB technology from different aspects to achieve different short-range wireless requirements in data rates and rages. The design and analysis of link budget are also included as a significant concept design for a tunable IR-UWB system to satisfy different wireless short-range applications in a single solution. A comparative analysis of the nearest field proposals with the problem stated in this research is presented with their associated testbeds for implementations and validations.

\subsection{UWB Definition}

UWB is a radio technology that can be used for short-range communication systems with low-energy consumption by using a large portion of the radio spectrum. The most important applications of this technology are target sensor data collection, object tracking, and precision location. The latest definition of UWB technology is set by the FCC and the International Telecommunication Union Radio with regard to transmissions from antennas as emitted signal bandwidth that exceeds $500 \mathrm{MHz}$ or $20 \%$ of the center frequency. The unlicensed use of UWB in the range between $3.1 \mathrm{GHz}$ and $10.6 \mathrm{GHz}$ has been authorized by the FCC on February 14, 2002. According to the FCC regulation, the limit for spectral density emission of a UWB emitter is $41.3 \mathrm{dBm} / \mathrm{MHz}$ as shown in Figure 1.

UWB is traditionally considered as a pulse radio because each transmitted pulse occupies the UWB bandwidth). Also, narrow-band carrier aggregates at least $500 \mathrm{MHz}$ (for example OFDM) can gain access to UWB spectrum.

By controlling pulse rate repetition from low to extremely high, UWB technology is suitable for a wide range of applications. These applications, which include radar and imaging systems, tend to use low repetition rates instead of multimedia communication systems that favor high repetition rates (Karapistoli, 2010) [2].

\subsubsection{UWB vs. Narrow Band}

The two main differences between UWB and other narrow-band or wide-band communication technologies are as follows. First, the bandwidth of UWB technology is much greater than that of any current technology. Second, narrow-band communication is achieved by modulating a sinusoidal carrier to transmit the required information. As a result, the output signal possesses a sinusoidal nature that occupies a narrow band in the frequency domain (FD). The unique characteristic of UWB technology is its ability to achieve wireless communication without using an RF carrier. UWB systems can be described as precisely timed, extremely short coded pulses that can be transmitted over a wide range of frequencies. The choice of specific waveform can be driven by system design and application requirements. A qualitative comparison between UWB technology and a typical narrow-band transceiver with regard to antenna, front end, as well as analog and digital basebands is illustrated in Figure 2 and summarized in Table 1 (Muqaibel, 2002; Barras, 2002) [3] [4].

Table 1 summarizes the main points of the comparison between UWB and narrow-band technologies.

\subsubsection{UWB Coexistence with Other Narrow-Band Wireless Technologies}

Although UWB technology has an extremely wide range of spectral applications, spectral overlapping with other relatively narrow-band systems cannot be excluded. A large number of studies have been conducted to ensure peaceful coexistence between UWB systems and other communication systems. Authors [5], investigate the different aspects of the coexistence between UWB and other Narrow-band systems as the proper understanding of the effects of the interference to/from UWB noses is essential for spectrum management. The findings from this conducted research experiments can be explained as the following: In dual case of Narrow-band systems affected by UWB interference it has been found that, the effects of a single UWB node interference are almost negligible, whereas this is not the case as the aggregate effect of many UWB nodes and interference should be taken into account in the system design to allow coexistence. Other researchers [6], proposed an interference mitigation technique for coexistence of Bi-phase UWB and other wideband systems such as Orthogonal Frequency Division Multiplexing (OFDM) and IEEE 802.11a Wireless Local Area Network (LAN) as the interference affect and degrade the system bit error performance. By using multi-carrier type transmission pulse and template 


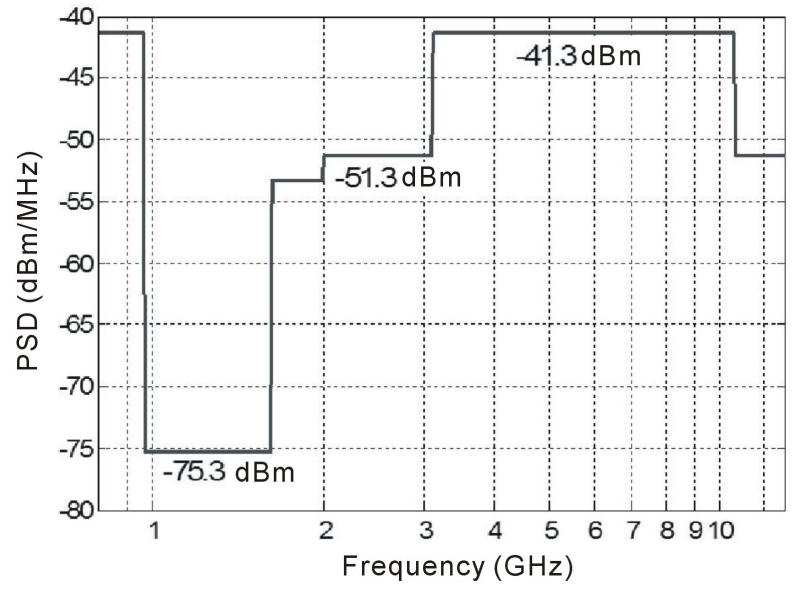

Figure 1. FCC emission mask for UWB [1].

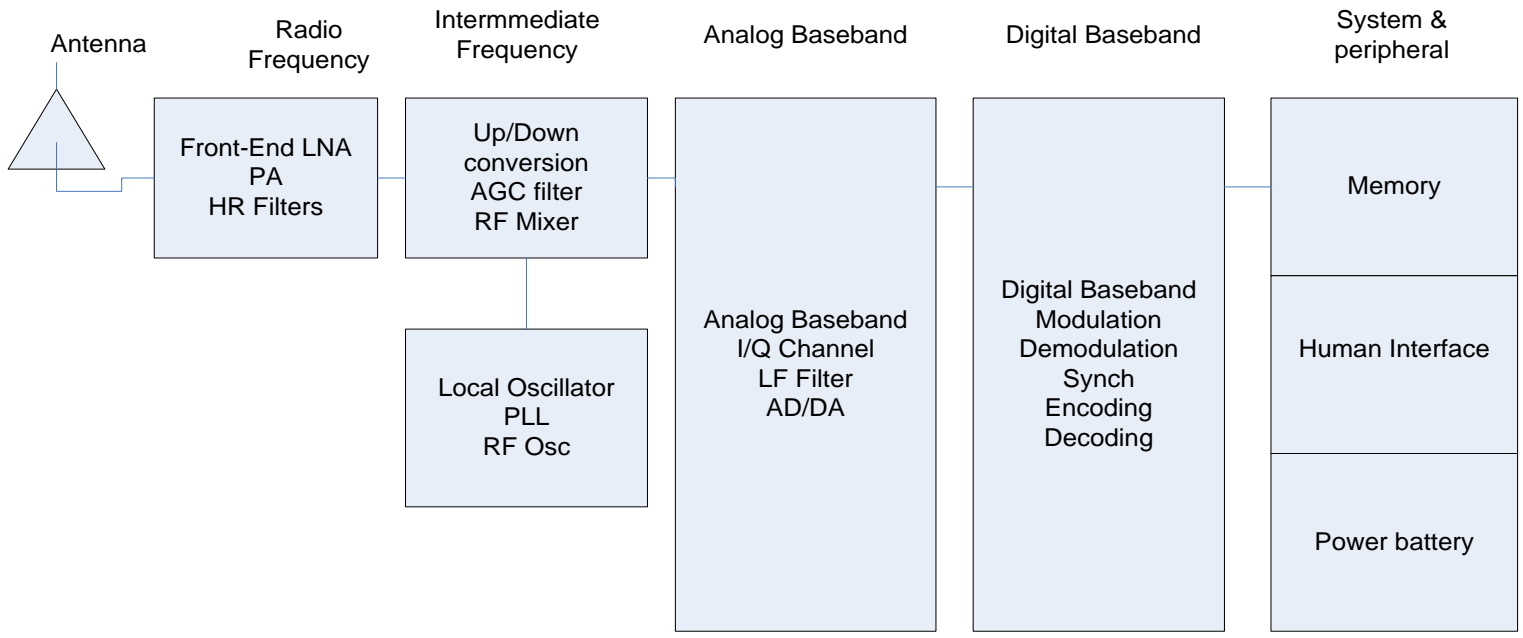

Narrowband Transceiver Architecture

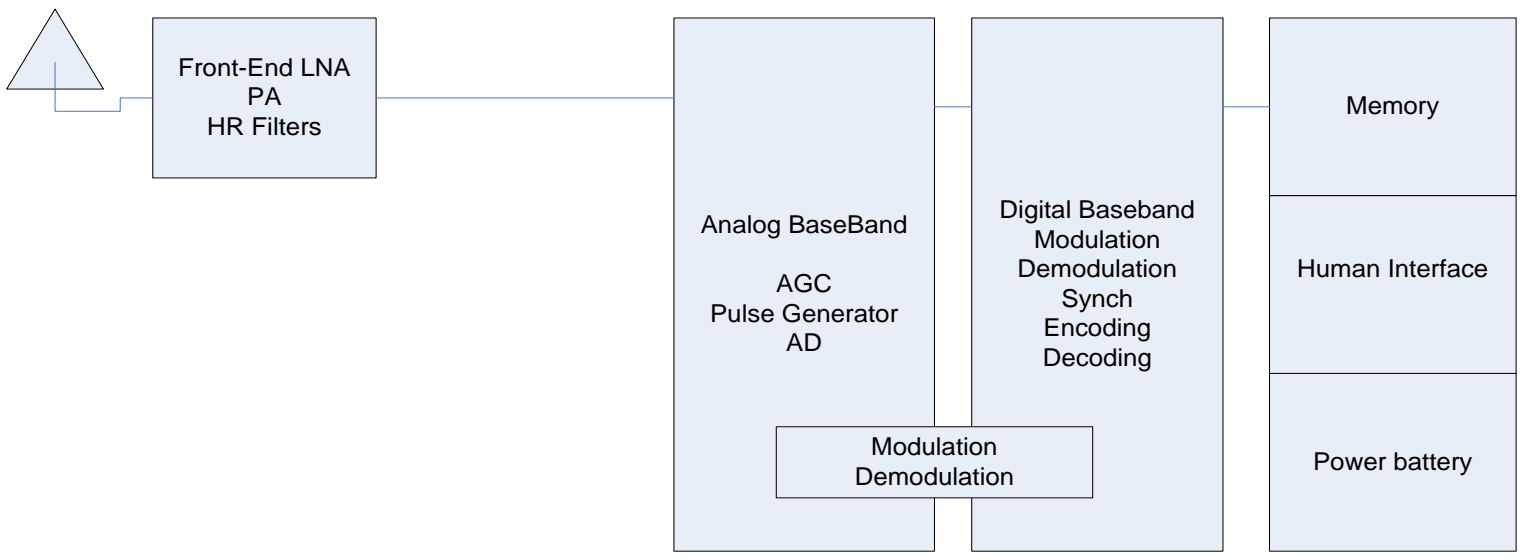

UWB Transceiver Architecture

Figure 2. Comparison between narrow-band and UWB receiver structures. 
Table 1. Comparison narrow-band and UWB communication systems.

\begin{tabular}{|c|c|c|}
\hline & UWB & Narrow band \\
\hline Antennas & $\begin{array}{l}\text { - Antenna should be small with gain and wide } \\
\text { bandwidth. } \\
\text { - Low-impedance antenna and good wide-band } \\
\text { matching } \\
\text { - Codesign is necessary between antenna and front } \\
\text { end. }\end{array}$ & $\begin{array}{l}\text { - Small high-Q antenna can be easily } \\
\text { achieved with good gain. } \\
\text { - With a } 50 \Omega \text { impedance and easy to match } \\
\text { - Antenna and front end can be designed } \\
\text { independently. }\end{array}$ \\
\hline RF front end & $\begin{array}{l}\text { - Wide-band LNA are power consuming and hard to } \\
\text { match. } \\
\text { - Automatic gain control (AGC) is part of the front } \\
\text { end. } \\
\text { - Relaxed requirements on linearity } \\
\text { - Partial filtering can be achieved by the antenna. }\end{array}$ & $\begin{array}{l}\text { - Narrow-band LNA is easy to match. } \\
\text { nonh linearity requirements for } \\
\text { OFDM) } \\
\text { - Tough filtering is needed to satisfy } \\
\text { out-of-band emission. }\end{array}$ \\
\hline Intermediate frequency & Not needed & AGC, mixer, RF oscillator, PLL \\
\hline Analog baseband & $\begin{array}{l}\text { Needs very high bandwidth } \mathrm{A} / \mathrm{D} \text { converter } \\
\text { digital sampling oscillator techniques }\end{array}$ & Small bandwidth A/D converter \\
\hline Digital baseband & $\begin{array}{ll}\text { - } & \text { Coherent detection } \\
\text { - } & \text { Very fine time resolution } \\
\text { - } & \text { Precise time references }\end{array}$ & non-coherent detection \\
\hline Channel aspects & Not yet completely known but studies are ongoing & $\begin{array}{l}\text { Narrow-band channel are well } \\
\text { characterized (fading model). }\end{array}$ \\
\hline
\end{tabular}

waveform as mitigation interference technique, better coexistence of different wideband systems can be achieved. With a careful selection of the frequency range of UWB pulse-controlled system and link budget settings, particularly for coverage ranges, a minimal interference and peaceful coexistence between UWB and other communication systems can be achieved [7].

\subsubsection{UWB as a Promising Wireless Short-Range Technology}

Short-range wireless communication is well deployed in many fields as its convenient, low power consumption and peer to peer communication [8]. Impulse based ultra wideband (IR-UWB) can be considered as a promising alternative technology for ultra wideband communications. The unique features of IR-UWB can be determined as, instead of modulating information on a carrier as in current wireless communication technologies data transmission is achieved as a coded series of very narrow pulses ( less than a nanosecond duration). In IR-UWB devices are smaller and cheaper with higher data rates for transmission with a method of sending information considered robust against multipath reflections, secure and power efficient (Kraemer, 2009) [9]. This technology has numerous commercial applications, including cable replacement for multimedia devices; high-speed area networking (e.g., PANs). In addition, real-time object tracking and asset tagging, through-wall or ground-penetrating radar imaging, and obstacle and vehicle collision detection [10]-[12] can also be applied.

\subsubsection{UWB Techniques and Modulations}

Two possible techniques can be used to implement UWB communication, namely, IR-UWB and multicarrier UWB. IR-UWB transmitter generates short pulses (nanoseconds) to disperse energy at least $500 \mathrm{MHz}$ in bandwidth [13] [14]. Several valuable aspects of pulsed-based UWB can be explained as follows. Short pulses can propagate without an additional RF mixing stage [15] [16]. Thus, the baseband-like architecture with low-duty cycle signal guarantees low complexity and low power consumption. In addition, given that pulses are short in space, most signal reflections are free from overlapping with the original reflection, thus showing a good level of resistance in severe multipath environments. The high amount of available bandwidth will provide an efficient time-domain (TD) resolution that ensures high accuracy in location and tracking applications. The noiselike signal with its ultra bandwidth provides robust and high-speed communication links, with high-processing speed, long operation range, and high security. The second method of UWB communication system, that is, the multicarrier or multiband UWB (MB-UWB), uses OFDM techniques to transmit information on each of the sub-band. On one hand, UWB-OFDM has several good features. On the other hand, UWB-OFDM requires up 
and down conversions and is sensitive to inaccuracies in frequency, time, and phase. In addition, the nonlinear character of the amplification will destroy the orthogonality of OFDM [17]. With such disadvantages, MBUWB is not applicable in low-power and low-cost applications. By comparing the two UWB techniques, Impulse_based UWB is assumed as a promising solution for short-distance communication, low-to-moderate data rate, and low-power radio communication with highly integrated systems, such as RFID and WSN, in a ubiquitous intelligent computing environment.

\subsubsection{Overview of Impulse-Based UWB Transceiver}

In IR-UWB, the generated short pulses can be modulated in different ways to transmit information. The modulation option depends on the type of application, design constraint, operation range, power consumption, hardware complexity, data rate, and capacity. The most well-known IR-UWB modulation options are pulse amplitude modulation (PAM), binary phase shift keying (BPSK), on-off keying, and pulse position modulation (PPM). According to [18], PPM with an orthogonal processing scheme can be considered as the best modulation option for IR-UWB technology, and the pulse shape choices of the PPM waveform could affect BER performance.

Accurate synchronization and channel estimation are required for accurate detection of pulses. Energy detectors and correlation detectors are the main two categories of IR-UWB receivers. Energy detection is based on the presence of a signal. This technique is applied in low-cost, easy implementations where no channel estimation is required but at the cost of poor BER. The correlation receiver is based on generating template signal acquired by bit and code synchronization, and possibly, channel estimation. The output is multiplied by the received signal, and then, the result is passed through an integrator and decision blocks. The rake receiver, wherein the bank of correlators are used to capture more multipath components and each finger can be synchronized to a specific multipath component, can be used in a multipath fading environment. The more fingers the rake receiver has, the more multipath component can be captured. However, channel estimation will be a great challenge that will make rake receivers too complicated and power-consuming. Therefore, rake receivers are not suitable for low-power and low-cost implementations [19].

\subsubsection{Impulse-Based UWB Standards and Protocols}

The standards for IR-UWB in WPAN can be understood through two amendments in IEEE 802.15.3 protocol for high-rate WPAN and IEEE 802.15.4 for low-rate WPAN in multipath fading environments. IEEE 802.15.3a [20] proposes that UWB PHY should provide high rate and speed (based on MB-OFDM) for applications involving imaging and multimedia. IEEE 802.15.4a was approved as an amendment to IEEE Standard 802.15.4 in March 2007. This protocol uses time-hopping (TH) and DS spectrum in spreading the techniques of the entire available spectrum. The main objective is to provide UWB communication with high-precision ranging and location tracking, high throughput, ultra-low power consumption with good scalability to data rates, and longer ranges [21] [22].

\section{Potential Applications of Impulse-Based UWB over WPANs}

Recently, UWB-based commercial applications have generated considerable interest because this technology can be used for low cost with excellent TD resolution that can be facilitated for localization and tracking applications [23]. Moreover, this technology shows a high-level flexibility at the PHY design level, thus allowing tunable generated pulses at different transmission rates. Therefore, high-data-rate and low-data-rate wireless sensor infrastructure can be obtained. The following subsections introduce different UWB-based wireless infrastructure in various application areas.

\subsection{Impulse-Based UWB High Data-Rate WPAN}

UWB communication systems can provide high data rates with multi-user data communication by carefully designing orthogonal pulses at the PHY level. This feature makes UWB a promising radio technology for networks that deliver high data rates in short ranges [24]. A number of these applications, wherein UWB pulses for high data rates can be commercialized products, can be seen in UWB-USB adapters [25] and medical imaging [26] [27].

\subsection{Impulse-Based UWB Low Data-Rate WPAN}

Low-data-rate UWB systems using TH impulse techniques (compliant with IEEE 802.15.4a protocol) are main- 
ly proposed for localization and positioning systems [28]. Several recently commercialized applications of this technology are available as UWB-RFID systems for active and passive tags for real-time detection, tracking, and remote monitoring [29]. RFID and WSN are both network infrastructure with low data rates in short distances. IR-TH UWB (IEEE 802.15.4a) is a suitable choice for the system design of such infrastructure.

\subsection{IR-UWB Radar Sensor Networks}

Vehicle obstacle avoidance, human body detection and tracking, object recognition, and biomedical imaging for biomechanics assessments are efficient UWB radar applications [30]. High-resolution IR-UWB pulses (very short pulses in UWB) can be used for high-precision radar. The development of compact and low-cost UWB radar has received considerable research attention recently for radar applications in military surveillance, medical remote mentoring, and collision avoidance systems [31].

\section{Tunable Impulse-Based UW}

IR-UWB is a highly tunable technology with regard to utilization of spectrum and transmission of data rates. Shaping the pulses of IR-UWB is a significant technique because of the impulsive nature of the carrier to match with network operating principles, such as the FCC emission mask [32] [33]. The tuning flexibility of IR-UWB allows reconfiguration by controlling signal parameters at the PHY level. Link budget is analyzed with regard to SNR and BER, as well as the link throughput, to evaluate system performance. System optimization can be achieved by dynamically controlling signal parameters according to certain QoS requirements.

Trade-off generally exists between the three main variables (BER, data rates, and distance) in any wireless communication system. Achieving the first two desirable variables will be at the cost of the third (for example, low BER with high data rate for a short-distance system or high BER with high data rate for a long-distance environment). This trade-off flexibility of the three main wireless variables is considerably highlighted in this research through link budget design and analysis. Through modeling, simulating IR-UWB communication, and statistically analyzing obtained results from the conducted experiments, the system can be evaluated and tuned for a specific link budget in certain wireless applications. This task can be achieved as a reconfigurable IR-UWB system with flexibility to optimize system performance according to a QoS weighing function designed at the link budget and implemented in the MAC layer.

\section{Review of the State of Art of IR-UWB as a Dynamic Short-Range Wireless Solution}

This section reviews studies on the design and implementation of impulse-based UWB systems in short-range applications. This section is divided into three main parts. The first part reviews recent UWB-WPAN standards and applications. The second part investigates recent advances in IR-UWB transceivers. The third part discusses IR-UWB performance analysis for specific link budget application requirements.

The objectives of this study are to analyze first the features of recent UWB technologies and then to evaluate their recent and expected future requirements. IR-UWB has been reviewed in literature with special attention on the advantages of this technology in short-range environments. The unique flexibility of IR-UWB to achieve different application requirements as a tunable technology is highlighted along with IR-UWB cross-layer design proposals in literature. Different performance evaluation criteria for various IR-UWB requirements are investigated to validate link budget design.

Concluding remarks from literature show that the advantages and high level of flexibility of IR-UWB can be used on a tunable IR-UWB platform by integrating both RFID and WSNs with performance evaluation to validate a specific link budget design.

\subsection{Comparison of IR-UWB with Other Wireless Short-Range Protocols}

Short-range wireless communication (within a distance of less than 100 meters) is the fastest growing segment of RF/wireless engineering. The four popular wireless standards for short-range wireless communications are Bluetooth $\odot$ (IEEE 802.15.1), UWB (IEEE 802.15.3 and IEEE 802.15.4a), ZigBee (IEEE 802.15.4), and Wi-Fi (IEEE 802.11) as shown in Figure 3. Bluetooth is intended for wireless keyboards, mice, and hands-free headsets. UWB is designed for high-data-rate multimedia links. ZigBee is mainly used for reliable wireless monitoring and network control. Wi-Fi is focused on computer-to-computer connection of cable networks. 


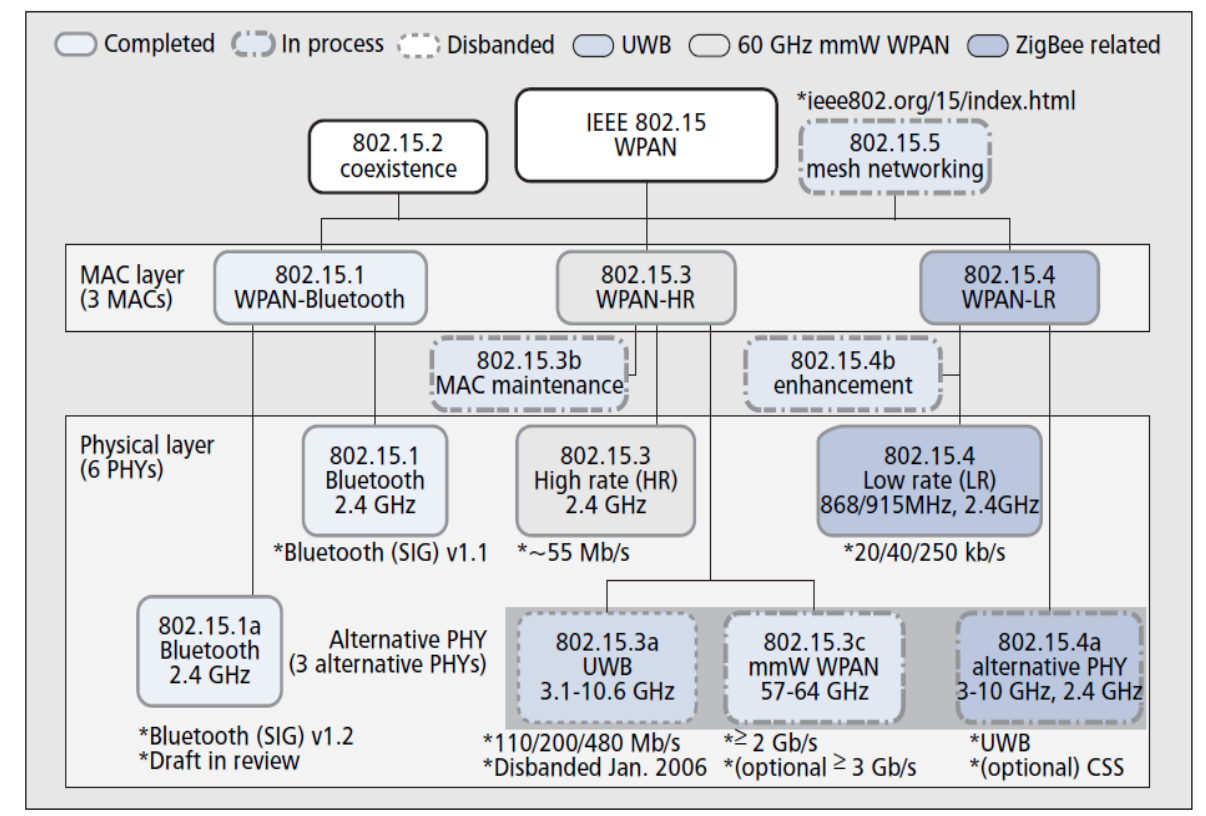

Figure 3. Wireless short-range communication protocols [34].

UWB and Wi-Fi support higher data rates, whereas Bluetooth and ZigBee support lower rates.

Four trends that drive short-range wireless systems, in general, and UWB, in particular, have been developed recently. These trends can be explained as follows.

- The growing demand for wireless technologies that can be integrated into small portable devices. These technologies can achieve higher bandwidths and data rates with lower cost and power consumption than currently available technologies.

- Dealing with mixed-media content (texts, graphics, and videos). Each element should be displayed in higher resolution with proper resource allocation for better links, throughputs, and QoS.

- The increasing demand for high-speed wireless communication systems similar to wired access in enterprises, homes, and public areas. Concern has been raised with regard to enabling high-speed, short-range wireless networking to traffic data at gigabit per second (Gbps) for business applications, such as linking a handset to a TV or a projector.

- Reducing the cost and size of the semiconductor, with less power consumption for signal processing, to supply markets with products that are more innovative, faster, and with lower cost.

Both RFID systems and WSNs can be considered as short-range and low-power wireless systems [35]. IR-UWB can be considered as a good candidate for future systems and applications in short-range wireless systems with additional advantages compared with RFID and WSNs, as shown in the succeeding paragraphs.

Wireless sensors/tags are used for auto-detection, including RFID systems, to improve the performance of management and control systems. Such improvements add value to supply chain management for successful final product manufacturing and delivery. In addition, reduces traffic problems through contactless security for check-in and check-out functions, and for allowing access control to staff/equipment with minimized system errors. For these reasons, RFID communication is expected to be prevalent in future daily living. RFID standards have been established in literature. These standards are mainly proposed for specific RFID frequencies and applications. Different RFID applications also require different software; by contrast, hardware components are common to all applications [36]. Recently, RFID application has generated great interest in digital smart indoor environments, including warehouses, clinics, and campuses, wherein wireless tags are deployed for monitoring, access control, and tracking. UWB tags have distinct advantages over other RFID solutions. UWB-RFID technology uses low-power signal spread over a wide range of frequencies (mostly operating from $3.1 \mathrm{GHz}$ to 10.6 GHz). UWB provides long line of sight (LOS) (reaching up to 200 meters in certain settings) compared with RFID systems. UWB-RFID is suitable for environments where sensitive equipment is found, including hospitals or medical clinics, because UWB signal is weak in certain frequencies, and thus, interference is minimal. In ad- 
dition, UWB signal is physically secured as a result of weak signal spreading over wide ranges of frequencies, thus making the signal difficult to detect and interpret. UWB transceiver architecture is less complicated than conventional narrow-band RFID nodes and tags, thus resulting in a carrier-free and almost digital architecture of UWB-RFID tags [37].

WSNs and RFID systems have common design constraints with different functionalities. RFID systems are used mainly for detection, whereas WSNs are for collecting, processing, and sending information to the base station for decision making or taking specific actions [38]. Design constraints of a WSN depend mainly on the application objectives and environments. Recently, a large number of studies have proposed WSNs for several emerging applications as shown in the following paragraphs.

WSN is used for environmental monitoring and decision making as an alert system in hazardous environments [39] as well as for supporting intelligent transportation systems to provide vehicles with information about surrounding traffic environments [40]. In food and agriculture industries, WSNs can be used for environmental monitoring in precision agriculture [41]. WSNs can be used to monitor chimerical reactions and to model temperature variations [42]. Low-power wireless transceivers can be used to send and receive video and audio data in surveillance applications, where large-scale networks of video sensors (wireless multimedia sensor Networks) can monitor public events, boarders, and private properties [43]. Moreover, Wearable biosensors are deployed for various applications in the medical field, such as wireless nurse calling systems or alarms [44].

Studies on WSNs are mainly focused on routing algorithms to reduce data aggregation between nodes and power consumption given that communication between nodes is the main factor affecting power consumption. Proposed techniques are mainly focused on limiting data aggregation by using several techniques on compression and aggregation, as well as for optimal routing of minimum hops from mobile to sink nodes [45] [46].

RFID and WSN systems have been generally studied independently. Integrating these systems will enhance their capabilities for new potential applications with low-power consumption. The use of IR-UWB in wireless sensing/detection and identification can be described by the following points.

- IR-UWB can be used to secure RF radio link among WSN nodes or RFID tags. This function is a result of the unique physical properties of the pulses, which are extremely tiny compared with UWB signals, thus making data infeasible to detect or alter for intruders [47].

- IR-UWB can be adapted in WSNs or in active RFID tags for location detection and object tracking applications based on centimeter accuracy of location estimation [48].

- IR-UWB transceiver is a low-cost hardware because this technology is carrier-free and modulation is achieved without the need for a carrier signal. This feature significantly reduces receiver complexity because it eliminates the need to extract the transmitted signal from the carrier signal [49].

- IR-UWB can be considered as a good candidate for cognitive radios in smart-tagged sensor networks because this technology is secure, thus allowing multiple access, and highly adaptive to environmental changes and application requirements [50] [51] for efficient resource allocations.

- IR-UWB can be used for high- and low-data-rate applications in digital smart environments, including homes and [52].

\subsection{Designing IR-UWB Nodes as Cognitive Radio}

UWB signals are spread over a broad spectrum with a power level near the noise floor, thus these signals unavoidably overlap with existing narrow-band radios, such as cellular mobile communication, global positioning system, and wireless local area network (LAN) (e.g., IEEE 802.11a/b/g). The FCC defined the UWB signal and the spectrum mask to specify the level of power radiated by a UWB system. A UWB signal is generally near the thermal noise floor, and thus, UWB systems support signal ranges of up to approximately 10 meters unless a high-gain antenna is used [53]. Spectrum sensing and allocation using proper spectrum spreading techniques for $\mathrm{TH}$, such as PPM, or frequency hopping, such as MB-OFDM, are critical issues in designing cognitive UWB solutions [54]. A link budget template design can be used to plan the RF link of the suggested cognitive UWB node. The link budget template model determines the link parameters with their possible changes and values [55]. This concept can be used in the cross-layer design architecture for the MAC-aware PHY, which can dynamically sense QoS requirements of environmental conditions and applications [56]. Then, the PHY is reinstructed to change signal parameters for shaping, modulation, and coding. Such changes may result in different transmission rates and BER performances. Planning a cognitive UWB wireless solution is included in designing 
a link budget template beside the cross-layer architecture design to support low data rate UWB wireless functionality. This is applicable for system tracking, and medium-to-high data rates, such as wireless medical image transmission in various distance scenarios. In literature, UWB cognitive capabilities have been separately shown as link budget and cross-layer architecture based on different design aspects. The methodology proposed in this thesis combines link budget template design and analysis with cross-layer architecture to develop a UWB solution that dynamically senses performance dropping and adapts its signal physical parameters to different requirements. Working with these two levels of design for cognitive UWB provides a higher level of understanding of the UWB RF link by focusing on parameters that allow control of data transmission rates, sense channel condition changes, and respond dynamically for better resource allocation.

\section{IR-UWB as Integrator Solution for Wireless Sensing and Identification Infrastructures}

In this subsection, several of the most recent research activities (from 2008 to 2010) are considered on RFID advancements and added values by combining functionalities of RFID and WSN systems. [57], discussed the potential benefits of combining RFID and WSNs in a single structure and proposed a hybrid RFID and WSN (HRW), which consists of gateway RFID (GRFID) readers and hybrid smart nodes (HSNs). In HRW systems, instead of waiting for each tag to enter the reading zone of the RFID readers, a replica of information is sent through neighboring nodes based on several algorithms applied in both RFID readers and HSNs. Then, the packet is sent to GRFID readers if one of the replicas moves into the range of a GRFID. Compared with traditional RFID systems, HRW systems reduce deployment cost and enhance the ability of tags in updating delay. However, such systems also have limitations. First, they are proposed mainly as routing algorithms in WSNs without studying RF characteristics (the PHY design is not considered). Second, these systems are profitable only in large-scale wireless nodes.

A case study shows an integrated RFID and WSN systems in pervasive computing has been conducted [58]. The architecture of integration can be described as a prototype system for ZigBee-based RFID network implemented with the modules of an RF transceiver for read/write operations in the $13.56 \mathrm{MHz}$ high-frequency band. The ZigBee-based communication module is an onboard antenna for wireless sensors and an RF transceiver operating at 2.4 GHz compliant with IEEE 802.15.4 protocol. This case study has focused mainly on hardware implementation by using ZigBee protocol for WSNs and RFID systems without further discussing point-to-point radio communication and performance evaluation as PHY or MAC implementation to exhibit system behavior.

An integrated architectural technique has been proposed through the efforts of combining typical indoor RFID solutions with common outdoor WSN solutions to provide better monitoring systems for applications such as animal monitoring [59]. The application in open environments and the behavior of mobile objects are considered. Typical sensor node states of sensing, computing, routing, and communicating are highlighted. By incorporating an RFID reader, the node is verified as either idle or computing before sending the data. This type of research is limited because the flexibility of the system is shown mainly in the routing algorithm at the MAC layer without highlighting the reconfiguration of the system in dynamic environments. Given that the physical environment changes dynamically (channel conditions), QoS requirements also change and instructions from the MAC layer to the PHY are needed to allow the signal physical parameters to adapt.

\section{Analysis of Adaptable IR-UWB Radio}

The link budget in wireless communications determines signal quality and strength at the receiver side [60]. Careful design of the link is essential in establishing a valid RF to take place in an IR-UWB system restricted by FCC rules. Choosing proper IR-UWB radio parameters and settings (as improved modulations and coding schemes) is important in enhancing performance in terms of BER, data rates, and service coverage. Theoretically, the calculation of the received signal can be achieved if transmitter and antenna gains are known. Link budget settings, such as distances, frequencies, link types, and LOS settings, can be determined during real-time experiment settings. Link budget can be considered as a validation for the RF design. [61] [62] have proposed IR-UWB link budget models for near-field WPAN applications. Their studies cover variations in link budget and pulse shape in far-field applications. Validation is achieved as the agreement between simulation and the set of measurements.

High-data-rate WiMedia UWB products have been examined for link budget analysis in comprehensive mea- 
surements in office and residential environments [63] [64]. This proposed specific link budget is validated based on results obtained from several measurements from various distances ranging from $1 \mathrm{~m}$ to $20 \mathrm{~m}$. IR-UWB is considered as an ideal candidate for wireless short-range, high-speed, low-power, and low-cost indoor applications. Link budget estimation is critical in designing the matched filter at the receiver side to maximize SNR and to study the effects of waveform distortions [65]. The goal of numerous IR-UWB link budget measurement campaigns is to investigate signal propagation and behavior in indoor or outdoor short-distance scenarios to develop channel models. Moreover, receiver development has been investigated to specify communication parameters which can be adjusted to enhance system performance in real-time applications [66] [67]. IR-UWB outdoor measurement studies are designed and conducted mainly for monitoring and surveillance applications because extremely tiny UWB pulses provide fine resolutions for accurate object tracking. Link budget investigations of IR-UWB is a critical design aspect in the development of communication models for channel modeling, pulse shaping, and transceiver structure in low- and high-rate indoor and outdoor applications. Link budget analysis and design can provide a thorough understanding of IR-UWB parameters, which is considered as extremely helpful in the design of the communication PHY, MAC layer, and cross-layer design concepts.

\section{Link-Budget Design and Analysis for Proposed IR-UWB Short-Ranges Wireless Solutions}

This section highlights the role of link-budget design and analysis in designing IR-UWB short-range solutions. Link budget analysis involves physical layer design, digital baseband implementation and experimental indoor/outdoor validation for the proposed solution. Explanation of this concept can be shown clearly in some proposed solutions in literature. Wireless communication developers usually design their own link budget template and analyze it with the relevant physical parameters values and then they give the full-digital coherent architecture and corresponding baseband algorithms.

Authors (Oh 2009) [63] have designed impulse-radio ultra wideband (IR-UWB) system for precise ranging and low-rate communication. The design methodology involved a link budget analysis then the full digital transceiver along with the corresponding baseband receiver algorithms. The designed solution has been validated with experiments on ranging and positioning in indoor environments. The link budget design of the proposed solution can be explained as the following: The achieved network throughput, number of pulses per a burst, pulse duration, communication coverage, the transmitted signal power, minimum receiver sensitivity and the link margin. The solution design is planned with the link design and analysis with the relevant and proposed parameters values as shown in Table 2.

In statistically analyzing the multiuser interference of impulse radio ultra wideband (IR-UWB) as found in [69], the physical parameters of the signal are shown in Table 3 for the link designed as the transmitter and the receiver are located about 1 meter from the floor with distance between the transmitter and receiver was 1 to 1.5 meters. The measurements were being taken in strong multipath environments.

\section{Cross-Layer Optimized IR-UWB Solutions}

In traditional wireless systems designs, there is a clear boundary between the PHY and MAC layers. The main goal of the MAC layer is to organize the access to the PHY layer as the physical layer is responsible for actual transmission of the information between the nodes. In general, there is no interaction between the two layers as the MAC layer has no control over the transmission rate and power generated by the PHY. In PHY-aware MAC designs, MAC layer can access some or all the parameters of the PHY layer. As example, the power or rate can be dynamically adapted as mitigation technique for level of interference [70].

Different optimizations have been proposed in literature to overcome constrains of using IR-UWB wireless nodes for future applications. The proposals for new applications of IR-UWB wireless nodes created challenges and problems that need to be addressed. The most efficient way of solving these problems is by using the cross-layer approaches to consider the behavior of protocols at each layer. This section surveys the key problems of future IR-UWB wireless nodes and the available cross-layer solutions for them.

Mobility aspects in future wireless networks have been highlighted in [71] as various services should be available with convenient throughput. This research work analyzed the design of physical layer aware medium access control for the purpose of self-organized low data rate, low power impulse radio ultra wideband (IR-UWB). Author's main concerns are the network energy consumption then the achieved data rates to under- 
Table 2. IR-UWB link budget for precise ranging low rate communication (Oh , 2009) [68].

\begin{tabular}{|c|c|c|}
\hline Parameters & Unit & Values \\
\hline Throughput [Rb] & Mbps & 0.85 \\
\hline Distance [d] & Meter & 30 \\
\hline Avg. Tx Power $\left[\mathrm{P}_{\mathrm{t}}=41.3 \mathrm{dBM} / \mathrm{MHz}+10 \log (\mathrm{BW})\right]$ & $\mathrm{dBm}$ & -14.3 \\
\hline Duty Gain (DG) & $\mathrm{dB}$ & 15.1 \\
\hline Tx Peak Power $\left[P_{t p=} P t+10 \log 10(D g)\right]$ & $\mathrm{dBm}$ & 0.7 \\
\hline Center Frequency [Fc] & $\mathrm{Hz}$ & $4.49 \mathrm{E}+09$ \\
\hline Path loss 1 Meter [L1 = $20 \log (4 \mathrm{pi}+\mathrm{fc} / \mathrm{c})$ & $\mathrm{dB}$ & 45.5 \\
\hline Path loss D Meter [L2 = $20 \log (\mathrm{d})]$ & $\mathrm{dB}$ & 29.5 \\
\hline Rx Power $[\mathrm{Pt}=\mathrm{Pt}-\mathrm{L} 1-\mathrm{L} 2]$ & $\mathrm{dBm}$ & -74.3 \\
\hline Rx Noise floor $\{N=-172+10 \log (B W)]$ & $\mathrm{dBm}$ & -87 \\
\hline Rx Noise Figure [Nf] & $\mathrm{dB}$ & 8.0 \\
\hline Rx Noise power $\left[\mathrm{Pn}=\mathrm{N}+\mathrm{N}_{\mathrm{f}}\right]$ & $\mathrm{dBm}$ & -79.0 \\
\hline Pulse per symbol [Np] & & 16 \\
\hline Processing gain [PG = $10 \log (\mathrm{Np})]$ & $\mathrm{dB}$ & 12.0 \\
\hline Minimum $E_{b} / N_{o}[\mathrm{~S}]$ & $\mathrm{dB}$ & 8.0 \\
\hline Implementation Loss [I] & $\mathrm{dB}$ & 3.0 \\
\hline Link Margin $[\mathrm{LM}=\mathrm{Pr}-\mathrm{Pn}-\mathrm{S}-\mathrm{I}-\mathrm{PG}]$ & $\mathrm{dB}$ & 5.8 \\
\hline Proposed Min. Rx Sensitivity Level [P min] & $\mathrm{dB}$ & -80.1 \\
\hline
\end{tabular}

Table 3. IR-UWB link budget signal physical parameters [69].

\begin{tabular}{cc}
\hline Parameter & Value \\
\hline $\mathrm{T}_{\mathrm{p}}$ (Transmitted pulse duration) & $2 \mathrm{Ns}$ \\
$\mathrm{T}_{\mathrm{C}}$ ( Chip Time) & $2 \mathrm{Ns}$ \\
$\mathrm{N}_{\mathrm{c}}$ ( Number of chips) & 128 \\
$\mathrm{~N}_{\mathrm{f}}$ ( Number of frames) & 128 \\
$\mathrm{~T}_{\mathrm{p}}^{(i)}$ (Delay duration of UWB pulse ) & Random \\
$\mathrm{C}_{\mathrm{m}}^{(i)}$ (user-dependent pseudo-random code) & Random \\
$\mathrm{N}_{\mathrm{u}}$ (No. of asynchronous users) & 2 \\
Sampling Frequency & $2 \mathrm{GHz}$ \\
Central Frequency & $4.05 \mathrm{GHz}$ \\
Bandwidth & $500 \mathrm{MHz}$ \\
\hline
\end{tabular}

stand the design tradeoff in very low power network. In their cross-layer design, they showed that, the rate control is needed as the rate (pulse modulation and coding) should be determined to some predefined value enough to be workable for all channel conditions. The relationship between the transmission rate and the power consumption is defined as: low transmission rate is longer lasting packet transmission and thus more energy is consumed.

The purpose of cross-layer MAC design for IR-UWB networks in [72] is to highlight the benefits of controlling the channel access rate of IR-UWB. The access rate is determined by pulse rate (pulses/sec), modulations and error coding rate. The benefits have been quantified as network throughput results under peer-to-peer and star network topologies. Simulated results show improved link quality of the proposed MAC layer design. This can be explained as the structure of the IR-UWB signal minimizes the total interference and maximize the network throughput.

Accurate ranging and positioning for IR-UWB sensor networks is the concern of the MAC-aware PHY layer design [73] [74]. The MAC layer is adapted to low data rate LDR-UWB and ranging detection is based on the exchange of control packets then, the ranging information provided by the MAC is considered as input to a distributed positioning protocol. Performance evaluation is performed in simulation of positioned terminals and the percentage of positioning error. Results show excellent ranging accuracy MAC-location aware design. 
Cross-layer design for distributed signal detection under resource constraints scenarios is presentenced in [75]. The objective of this research is to minimize the probability of error of distributed system in a fixed level of total transmission power. Results show considerable performance gains in comparison with uniform power assignment for both parallel and serial network topologies.

\section{IR-UWB Testbeds}

Researchers in wireless technologies field usually refer to simulations and experiments according to their particular research needs. Although, simulators do not always reflect real-world scenarios, they provide full control for researchers to investigate wireless network behaviors. The behavioral differences between simulation and real-world testbeds experiments can be investigated at the PHY layer level as well as the MAC layer level. In PHY layer, the received signal strength in experiments is in general different than simulation due to antenna diversity [76]. Path loss is considered the main factor in simulator channel modeling and can be configured to match with real-world behavior. At MAC layer level, simulators and testbeds response differently in heavy traffic scenarios as the performance degradation in simulators is less obvious than in experiments.

Many proposals for different IR-UWB testbeds utilized for different aspects of optimization and for new applications can be found in literature. For example, researchers from china proposed testbed for low complexity, low cost and low power consumption UWB PHY [77]. The proposed testbed validates the high data rate of wireless connectivity of IR-UWB in real network. The purpose of the testbed design is to satisfy the consumer multimedia industry need in short range communications. Hardware prototyping and implementation are used for performance evaluation and validation for the testbed. Testbed of IR-UWB for ranging and positioning is described in [78]. The variances for ranging and positioning are computed from the transmitted and received signals. Mitigation technique to minimize the impact of the ranging error on the positioning accuracy is been approved as increasing the number of receivers.

Testbed implemented as statistical modeling for multiuser interference (MUI) of IR-UWB systems to estimate the channel condition is presented in [79]. This testbed design uses measurements under office line of sight (LOS) for validation purpose then the statistical properties of MUI is analyzed in frequency domain.

From the different testbed designs and aspects its clearly that, proposals for optimized solutions of IR-UWB systems are first investigated as cross-layer optimized solutions, link budget design and analysis for the signal and RF parameters of interests and then the proposed testbed analyze and validate the findings in simulators as well as in real-world experiments.

\section{Finding Remarks from Literature}

Short-range wireless communication with distances of less than 100 meters (such as RFID, Zigbee, Bluetooth and UWB) is the most rapidly growing segment in wireless engineering. Especially, UWB base communication show attractive features as low power, low cost, high data rate with the ability of location aware. All these attractive features are suitable for future ubiquitous environments.

UWB can be categorized as carrier-less UWB, single carrier and multi-carrier UWB. Carrier-less impulse radio (or IR-UWB) is the most interesting approach of UWB communications. It uses very short, low duty-cycle impulse occupying a single band of several GHz. Among the three UWB types, IR-UWB has the advantages of a simple transceiver with less components and low-power transmission.

Numerous studies have attempt to utilize UWB technology for identification (UWB-RFID), location (UWBbased location), sensing (UWB-based sensor network) and connectivity (UWB over WPAN). Fortunately, IR-UWB is highly tunable at the physical layer level with flexibility for different signal modulations, coding and shaping to support different transmission rates.

Despite the fact that (IR-UWB) radio is considered the most suitable candidate for next generation transceivers to support power constrained applications (such as wireless sensors and body sensors network), still many challenges need to be addressed before the successfully widely deployment of this technology in the market. Optimized IR-UWB solutions are the research topics with high concern recently.

The flexibility in IR-UWB system design for adaptive data rate with optimized throughput for optimal transmission mode can be achieved by cross-layer communication architecture. In this cross-layer architecture design, the physical layer is capable of adaptive modulation and coding (AMC) scheme to improve bandwidth efficiency over time-varying channel. By jointly considering channel characterization, physical layer parameters for 
signal shaping and coding and the link budget design and analysis, the analytical results can provide cross-layer for data transmission and throughput optimizations to ensure certain level of the quality of services in UWB networks. Simulations of the proposed communication system under different channel models and experimental statistical results of the received signal in different indoor/outdoor environments is the testbed to validate the analysis and then to proof the concept of the proposed cross-layer optimization of IR-UWB in short-range communication.

Table 4 summarizes the finding remarks of near-field and latest studies on link budget designs and reconfigurable IR-UWB system implementations as cross-layer designed architectures. The comparison among discussions mainly focuses on the proposed ideas, the proof of concept methodology used to validate such proposals,

Table 4. Comparison of related studies on link budget analysis of IR-UWB.

\begin{tabular}{|c|c|c|c|c|c|c|}
\hline Research & Proposed model & Simulations & $\begin{array}{l}\text { Set of conducted } \\
\text { experiments }\end{array}$ & $\begin{array}{l}\text { Purpose of link } \\
\text { budget investigation }\end{array}$ & Validation & Applications \\
\hline $\begin{array}{c}\text { Irahhauten, Z. } \\
\text { et al., } 2008 \\
\text { [80] }\end{array}$ & $\begin{array}{l}\text { UWB link budget } \\
\text { in near field } \\
\text { nitially affected } \\
\text { by the phase error } \\
\text { dependent on the } \\
\text { considered } \\
\text { bandwidth. }\end{array}$ & $\begin{array}{l}\text { The received power, } \\
\text { as a function of } \\
\text { distance for different } \\
\text { dipole antennas, is } \\
\text { compared with the } \\
\text { result obtained from } \\
\text { the calculation and } \\
\text { simulation processes. }\end{array}$ & $\begin{array}{l}\text { Measurements have } \\
\text { been conducted at } \\
\text { different distances } \\
\text { using TD techniques. }\end{array}$ & $\begin{array}{l}\text { Study the effects of } \\
\text { antenna parameters, } \\
\text { including size and } \\
\text { distance between } \\
\text { antennas }\end{array}$ & $\begin{array}{l}\text { Validation has } \\
\text { been achieved } \\
\text { based on the } \\
\text { agreement among } \\
\text { calculated results, } \\
\text { simulation, and } \\
\text { experiments. }\end{array}$ & $\begin{array}{c}\text { Extremely } \\
\text { short WPAN } \\
\text { applications }\end{array}$ \\
\hline $\begin{array}{l}\text { Volos, H.I. et al., } \\
2009 \text { [81] }\end{array}$ & $\begin{array}{c}\text { The use of an } \\
\text { antenna-pulse } \\
\text { coupling gain for } \\
\text { specific Tx-Rx } \\
\text { pairs }\end{array}$ & None & $\begin{array}{l}\text { Several TD } \\
\text { measurements ranging } \\
\text { from } 1 \mathrm{~m} \text { to } 20 \mathrm{~m} \text { to } \\
\text { estimate the received } \\
\text { Eb/No and to compare } \\
\text { between the traditional } \\
\text { Friss formula and the } \\
\text { proposed coupling } \\
\text { gain method }\end{array}$ & $\begin{array}{c}\text { Overcome } \\
\text { narrow-band } \\
\text { limitation in } \\
\text { traditional link } \\
\text { budget by proposing } \\
\text { the use of an } \\
\text { antenna-pulse } \\
\text { coupling gain to } \\
\text { estimate the } \\
\text { received power }\end{array}$ & $\begin{array}{l}\text { Verification of } \\
\text { the accuracy of } \\
\text { the proposed } \\
\text { method is } \\
\text { achieved by } \\
\text { several } \\
\text { measurements } \\
\text { taken from } 1 \mathrm{~m} \\
\text { to } 20 \mathrm{~m} \text {. }\end{array}$ & $\begin{array}{c}\text { Extremely } \\
\text { short WPAN } \\
\text { applications }\end{array}$ \\
\hline $\begin{array}{l}\text { Uengkittikul, } \\
\text { P. and S. } \\
\text { Promwong, } \\
2009 \\
{[82]}\end{array}$ & $\begin{array}{l}\text { Investigations on } \\
\text { free-space link } \\
\text { budget evaluation } \\
\text { scheme as the } \\
\text { transmission gain of } \\
\text { IR-UWB systems, } \\
\text { which consider the } \\
\text { distortion of the } \\
\text { transmitted } \\
\text { waveform caused } \\
\text { by the antenna }\end{array}$ & f & $\begin{array}{l}\text { Biconical antenna } \\
\text { and periodic dipole } \\
\text { antenna (LPDA) tested } \\
\text { in the range of } 1 \mathrm{GHz} \\
\text { to } 12.4 \mathrm{GHz} \text { to show } \\
\text { the gain in different } \\
\text { orientation angles }\end{array}$ & $\begin{array}{l}\text { Evaluate link budget } \\
\text { of IR-UWB as the } \\
\text { effects of two } \\
\text { broadband antennas } \\
\text { on the gain of the } \\
\text { transmitted } \\
\text { waveform }\end{array}$ & $\begin{array}{c}\text { Validation is } \\
\text { achieved based } \\
\text { on the comparison } \\
\text { between two } \\
\text { types of } \\
\text { broadband } \\
\text { antenna in terms } \\
\text { of transmission } \\
\text { gain. }\end{array}$ & $\begin{array}{l}\text { Extremely short } \\
\text { WPAN, with a } \\
\text { distance of } 1 \mathrm{~m} \\
\text { between sending } \\
\text { and receiving } \\
\text { antennas }\end{array}$ \\
\hline $\begin{array}{c}\text { Liu, L. et al., } \\
2009 \\
{[83]}\end{array}$ & $\begin{array}{c}\text { Modeling human } \\
\text { blockage effects in } \\
\text { LOS UWB } \\
\text { WiMedia } \\
\text { communication link }\end{array}$ & $\begin{array}{l}\text { Simulation has } \\
\text { been carried out to } \\
\text { evaluate human } \\
\text { blockages in three } \\
\text { WiMedia UWB } \\
\text { radio link setups. }\end{array}$ & $\begin{array}{l}\text { Tx and Rx antennas } \\
\text { are fixed with a } \\
\text { distance of } 3 \mathrm{~m} \text {, while } \\
\text { a person stands } \\
\text { between them to } \\
\text { block the LOS and } \\
\text { obtain channel } \\
\text { statistical parameters. }\end{array}$ & $\begin{array}{l}\text { Study the effect of } \\
\text { human body } \\
\text { blockages on the } \\
\text { wireless link, and } \\
\text { then modeling the } \\
\text { channel and } \\
\text { evaluating the } \\
\text { performance }\end{array}$ & $\begin{array}{l}\text { The proposed } \\
\text { model is validated } \\
\text { in different link } \\
\text { budget setups } \\
\text { with performance } \\
\text { evaluation. }\end{array}$ & $\begin{array}{l}\text { High-speed } \\
\text { short-range } \\
\text { wireless medical } \\
\text { applications }\end{array}$ \\
\hline $\begin{array}{c}\text { Aubin } \\
\text { LECOINTRE } \\
\text { et al., } 2008 \\
{[84]}\end{array}$ & $\begin{array}{l}\text { Reconfigurable } \\
\text { IR-UWB hardware } \\
\text { design for data rate, } \\
\text { spectrum, and } \\
\text { range }\end{array}$ & $\begin{array}{l}\text { Simulations have } \\
\text { been carried out } \\
\text { as performance } \\
\text { analysis with regard } \\
\text { to BER in different } \\
\text { IR-UWB settings }\end{array}$ & None & $\begin{array}{l}\text { Global solution } \\
\text { for distinct } \\
\text { applications with } \\
\text { different needs }\end{array}$ & $\begin{array}{l}\text { Validation is } \\
\text { achieved } \\
\text { according to } \\
\text { different budget } \\
\text { link settings } \\
\text { combined with } \\
\text { the performance } \\
\text { analysis for BER. }\end{array}$ & $\begin{array}{l}\text { Wireless } \\
\text { applications with } \\
\text { different needs } \\
\text { for data rates } \\
\text { and power } \\
\text { consumption }\end{array}$ \\
\hline
\end{tabular}


and the efficiency of the suggested applications and the testbeds for implementations. Studies on UWB have highlighted different aspects of using wireless short-range communication systems, and optimal solutions for future scenarios are needed. The purpose of the comparison presentation in the following table is to show the different analytical techniques used to validate the proposal of optimizing IR-UWB technique in short-ranges communication system. This includes the cross-layer architecture designs, the different aspects to link-budget analysis and the testbeds for implementations.

Table 5 presents tunable IR-UWB proposed solutions highlighting design methodologies of reconfigurable IR-UWB.

Table 4 and Table 5 present a comparison of the latest proposals for reconfigurable IR-UWB systems for different short-range applications. Based on these tables, a complete system design for cross-layer communication modeling has not been developed yet to exhibit the flexibility of the system with various distances and data rate requirements. The performance of the proposed models needs to be evaluated for each budget link setting.

Based on these studies, a dedicated test-bed design and implementation, including system theoretical analysis, real-time signal simulation of the proposed model, and statistical analysis of the captured data in real short-range environments, are conducted. This study aims to fill in the gaps left by previous works.

\section{Research Benchmarking}

Research benchmarking in this thesis can be defined as the process of rapidly capturing the essence of the IR-UWB field of knowledge with an interest in finding its leading edge for different application requirements and environments. Compared with similar fields of knowledge, the proposed tunable IR-UWB platform can be used for IR-UWB technology as a global platform for different wireless data transmission requirements in sim-

Table 5. Comparison of related studies on tunable IR-UWB at the system implementation.

\begin{tabular}{|c|c|c|}
\hline Authors & Research title & Summary of the research \\
\hline $\begin{array}{l}\text { Aubin LECOINTRE } \\
\text { et al., } 2008 \text { [85] }\end{array}$ & $\begin{array}{l}\text { Design and Hardware Implementation of a } \\
\text { Reconfigurable Mostly Digital IR-UWB Radio }\end{array}$ & $\begin{array}{c}\text { A proposal for reconfigurable IR-UWB implemented } \\
\text { in field-programmable gate array (FPGA) as proof of } \\
\text { concept for reconfigurable data rates, spectra, } \\
\text { and ranges, which satisfy the need for a wide } \\
\text { range of applications }\end{array}$ \\
\hline $\begin{array}{l}\text { A. Lecointre et al., } \\
\qquad 2010 \text { [86] }\end{array}$ & $\begin{array}{c}\text { A Largely Reconfigurable Impulse Radio } \\
\text { UWB Transceiver }\end{array}$ & $\begin{array}{l}\text { A proposal of an efficient digital baseband architecture } \\
\text { for reconfigurable IR-UWB transceiver. The capacity } \\
\text { for reconfiguration includes data rates, chip duration, } \\
\text { pulse duration, processing gain, and occupied } \\
\text { bandwidth. The other proposed FPGA programming } \\
\text { method validates this architecture proposal. }\end{array}$ \\
\hline Xia, L., 2008 [87] & $\begin{array}{l}\text { Low Power Amplitude and Spectrum } \\
\text { Tunable IR-UWB transmitter }\end{array}$ & $\begin{array}{l}\text { A low power with reduced complexity carrierless } \\
\text { transmitter with the ability to tune the spectrum. The } \\
\text { buffer can be turned off between pulse intervals to } \\
\text { reduce power consumption. The authors present the } \\
\text { implementation of the transmitter circuit with three } \\
\text { main parts: the pulse generator, output buffer, } \\
\text { and power control circuit. }\end{array}$ \\
\hline $\begin{array}{l}\text { Jun Li et al., } 2011 \\
\text { [88] }\end{array}$ & $\begin{array}{c}\text { Reconfigurable, Spectrally Efficient, High Data Rate } \\
\text { IR-UWB Transmitter Design Using a } \Delta-\Sigma \text { PLL Driven } \\
\text { ILO and a 7-Tap FIR Filter }\end{array}$ & $\begin{array}{c}\text { A prototype proposal for far infrared (FIR) } \\
\text { pulse-based UWB transmitter implemented in a } \\
90 \mathrm{~nm} \text { complementary metal-oxide-semiconductor. } \\
\text { The transmitter is a digitally reconfigurable 7-tap } \\
\text { FIR pulse generation which uses } \Delta-\Sigma \text { phase-locked } \\
\text { loop (PLL) for efficient frequency control and } \\
\text { 16-phase injection-locked oscillator. }\end{array}$ \\
\hline $\begin{array}{l}\text { Marian Verhelst et al., } \\
2008 \text { [89] }\end{array}$ & A Low Power, Reconfigurable IR-UWB System & $\begin{array}{l}\text { A proposal for a complete UWB transceiver system } \\
\text { which is fully reconfigurable in terms of bandwidth, } \\
\text { data rate, processing gain, and ranging accuracy. } \\
\text { The proposal validation is achieved as Integrated } \\
\text { Circuit implementation to demonstrate } \\
\text { power/flexibility trade-off in an integrated solution. }\end{array}$ \\
\hline
\end{tabular}


ple architecture. The proposed model can pave the era of smart sensor tags, where all wireless nodes can cooperate with each other dynamically, and respond with proper transmission rates and generated signals as cognitive radio candidates. The proposed architecture can be considered as a global solution for several wireless short-to medium ranges infrastructures, such as WSN and RFID systems and others, with which they share common design constraints, such as low power consumption and hardware complexity. Most proposed architectures for IR-UWB technology do not discuss in depth the full use of IR-UWB in low-power and complex wireless nodes for the flexibility of high and low data rates with different ranges. The methodologies proposed in this research aim to show the trade-off flexibility of IR-UWB technology with regard to the three main wireless variables (BER, data rates, and coverage ranges) to allow integration of the two wireless protocols (IEEE 802.5.3a and IEEE 802.5.4a) in a single infrastructure. In comparison between the proposed design in this thesis and similar proposals found in literature the proposed methodology can be illustrated in Figure 4. It shows the uniqueness of the proposed methodology and the results of the benchmarking research at the system level, as well as the performance evaluation.

\section{Summary}

IR-UWB technology has not yet been fully used, and numerous studies can be conducted to integrate several existing UWB-WPAN protocols and infrastructures with enhanced capabilities for dynamic responses of QoS requirements. The cross-layer design for IR-UWB communication is used with budget link design, and radio link performance has been presented at the end of reviewing in this paper. The performance evaluation can be accomplished in term of baseband real-time simulation for the communication link as well as RF statistical analysis of the received IR-UWB signal in real indoor/outdoor environments. This performance evaluation can

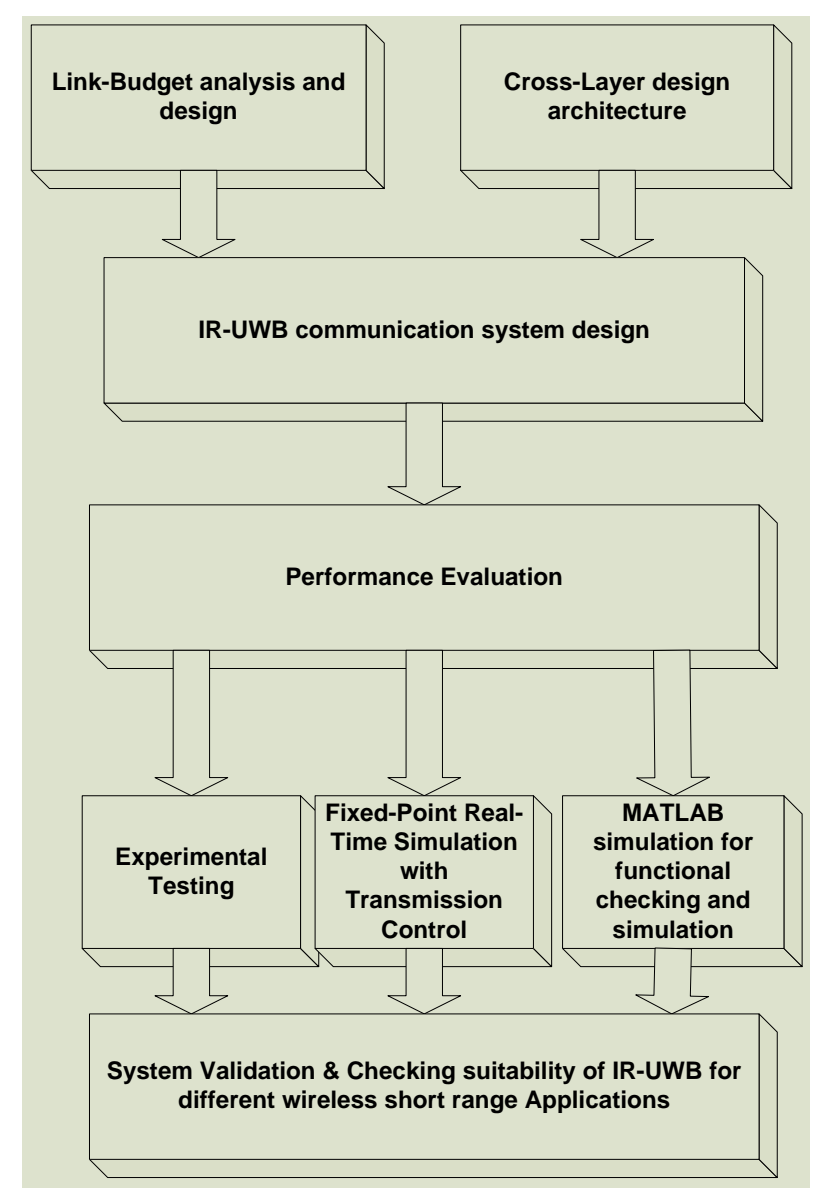

Figure 4. IR-UWB model for benchmarking at the system design level and the performance analysis. 
be considered to validate the proposed link design as a solution for future UWB node scenarios for optimal functionalities.

\section{Acknowledgments}

The authors would like to express their deepest gratitude and appreciation for Malaysia Ministry of High Education (MOHE) for the financial support under the grant coded as the following:

ERGS/2013/FKEKK/TK02/UTEM/03/05/E00021. As this finical support allows this work to be completed and published.

\section{References}

[1] Wood, S.R. and Aiello, R. (2008) Essentials of UWB. Cambridge University Press, Cambridge. http://dx.doi.org/10.1017/CBO9780511541070

[2] Karapistoli, E., Pavlidou, F.-N., Gragopoulos, I. and Tsetsinas, I. (2010) An Overview of the IEEE 802.15.4a Standard.

[3] Muqaibel, A. and Riad, S. (n.d.) Ultra Wideband vs. Narrowband Communications.

[4] Barras, D., Ellinger, F. and Jäckel, H. (n.d.) A Comparison between Ultra-Wideband and Narrowband Transceivers. 1-4.

[5] Chiani, M. and Giorgetti, A. (2009) Coexistence between UWB and Narrow-Band Wireless Communication Systems. Proceedings of the IEEE, 97, 231-254. http://dx.doi.org/10.1109/JPROC.2008.2008778

[6] Ohno, K. and Ikegami, T. (2008) Interference Mitigation Technique for Coexistence of Pulse-Based UWB and OFDM. (BioMed Central Ltd.) BioMed Central Ltd.

[7] Kouassi, K., Clavier, L., Doumbia, I. and Rolland, P.-A. (2011) Multiple-Access Interference Management in TH-PPM UWB Systems with Pulse Width Randomisation. 2011 IEEE International Conference on Ultra-Wideband (ICUWB), 165-169. http://dx.doi.org/10.1109/ICUWB.2011.6058818

[8] Hunn, N. (2010) Essentials of Short-Range Wireless. Cambridge University Press, Cambridge. http://dx.doi.org/10.1017/CBO9780511776991

[9] Jogi, S. and Choudhary, M. (2009) Ultra Wideband Demystified: Technologies, Applications, and System Design Considerations. River Publishers, Aalborg.

[10] Park, C. and Rappaport, T. (2007) Short-Range Wireless Communications for Next-Generation Networks: UWB, 60 GHz Millimeter-Wave WPAN, And ZigBee. IEEE Wireless Communications, 14, 70-78. http://dx.doi.org/10.1109/MWC.2007.4300986

[11] Sakkila, L., Tatkeu, C., Boukour, F., El-Hillali, Y., Rivenq, A. and Rouvean, J.M. (2008) UWB Radar System for Road Anti-Collision Application. 2008 3rd International Conference on Information and Communication Technologies: From Theory to Applications, Damascus, 7-11 April 2008, 1-6.

[12] Li, L., Tan, A.E.C., Jhamb, K. and Rambabu, K. (2012) Buried Object Characterization Using Ultra-Wideband Ground Penetrating Radar. IEEE Transactions on Microwave Theory and Techniques, 60, 2654-2664. http://dx.doi.org/10.1109/TMTT.2012.2198235

[13] Aleem, M.E.M.A. (n.d.) Ultra Wideband Systems and Modulation Techniques Using Different Gaussian Monopulse Waveforms. 1-8.

[14] Oppermann, I. (2004) UWB Theory and Applications. Wiley, Chichester. http://dx.doi.org/10.1002/0470869194

[15] La, R., Ingegneria, F., Maria, P. and Di, G. (2008) Time Reversal in UWB-Impulse Radio Communications.

[16] Rabbachin, A. (2008) Low Complexity UWB Receivers with Ranging Capabilities.

[17] Saberinia, E. and Tewfik, A.H. (2003) Multi-User UWB-OFDM Communications. 2003 IEEE Pacific Rim Conference on Communications Computers and Signal Processing (PACRIM 2003), 1, 127-130. http://dx.doi.org/10.1109/PACRIM.2003.1235735

[18] Svecova, M., Kocur, D., Zetik, R. and Rovnakova, J. (2010) Target Localization by a Multistatic UWB Radar. 20th International Conference Radioelektronika 2010, Brno, 19-21 April 2010, 1-4. http://dx.doi.org/10.1109/RADIOELEK.2010.5478568

[19] Yang, L., Ji, M., Gao, Z. and Zhang, W. (2011) Simulation Research on the Performance of IR-UWB Rake Receivers. 2011 2nd International Conference on Mechanic Automation and Control Engineering, Hohhot, 15-17 July 2011, 4392-4396.

[20] Tseng, Y. (2004) Efficient Resource Allocation for IEEE 802.15.3(a) Ad Hoc Networks. Lecture Notes in Computer 
Science, 3283, 128-142. http://dx.doi.org/10.1007/978-3-540-30179-0_12

http://www.worldcat.org/title/efficient-resource-allocation-for-ieee-802153a-ad-hoc-networks/oclc/108403615\&referer =brief_results

[21] De Dominicis, C. M., Flammini, A., Rinaldi, S., Sisinni, E., Cazzorla, A., Moschitta, A. and Carbone, P. (2011) HighPrecision UWB-Based Timestamping. 2011 IEEE International Symposium on Precision Clock Synchronization for Measurement, Control and Communication, Munich, 12-16 September 2011, 50-55. http://dx.doi.org/10.1109/ISPCS.2011.6070150

[22] Ye, R., Redfield, S. and Liu, H. (2010) High-Precision Indoor UWB Localization: Technical Challenges and Method. 2010 IEEE International Conference on Ultra-Wideband, 2, 1-4. http://dx.doi.org/10.1109/ICUWB.2010.5616888

[23] Cheok, K.C., Radovnikovich, M., Vempaty, P., Hudas, G.R., Overholt, J.L. and Fleck, P. (2010) UWB Tracking of Mobile Robots. 21st Annual IEEE International Symposium on Personal, Indoor and Mobile Radio Communications, Instanbul, 26-30 September 2010, 2615-2620. http://dx.doi.org/10.1109/PIMRC.2010.5671780

[24] Rehman, M.U., Wang, S., Liu, Y., Chen, S., Chen, X. and Parini, C.G. (2012) Achieving High Data Rate in MultibandOFDM UWB Over Power-Line Communication System. IEEE Transactions on Power Delivery, 27, 1172-1177. http://dx.doi.org/10.1109/TPWRD.2012.2193902

[25] Klunder, C. and Haseborg, J.L. (2008) An Estimation of the Backdoor Coupling of UWB Pulses on Commercial Wireless USB Adapters. 2008 IEEE International Symposium on Electromagnetic Compatibility, Detroit, 18-22 August 2008, 1-5. http://dx.doi.org/10.1109/ISEMC.2008.4652101

[26] Chen, X., Xu, S., Yin, H., Wang, W. and Wei, G. (2010) Potentials of IR-UWB Technology for Ubiquitous Computing. Personal and Ubiquitous Computing, 15, 75-84. http://dx.doi.org/10.1007/s00779-010-0299-3

[27] Watfa, M. (2012) E-Healthcare Systems and Wireless Communications Current and Future Challenges. Medical Information Science Reference, Hershey.

[28] Dardari, D., Luise, M., Emmanuele, A., Fontanella, D., Gezici, S., Gholami, M.R. and Kieffer, M. (2012) Satellite and Terrestrial Radio Positioning Techniques. Elsevier, Amsterdam.

[29] Zhou, Y., Law, C.L. and Xia, J. (2012) Ultra Low-Power UWB-RFID System for Precise Location-Aware Applications. 2012 IEEE Wireless Communications and Networking Conference Workshops (WCNCW), Paris, 1 April 2012, 154-158. http://dx.doi.org/10.1109/WCNCW.2012.6215480

[30] Chunming, W. and Guoliang, D. (2012) The Study of UWB Radar Life-Detection for Searching Human Subjects. Energy Procedia, 17, 1028-1033. http://dx.doi.org/10.1016/j.egypro.2012.02.203

[31] Taylor, J. (2012) Ultrawideband Radar: Applications and Design. Taylor \& Francis, Boca Raton. http://www.worldcat.org/title/ultrawideband-radar-applications-and-design/oclc/229022902\&referer=brief results

[32] Xia, L., Huang, Y. and Hong, Z. (2009) A Fully Integrated BPSK Amplitude and Spectrum Tunable Transmitter for IR-UWB System. Journal of Semiconductors, 30, Article ID: 015006. http://dx.doi.org/10.1088/1674-4926/30/1/015006

[33] Di Benedetto, M.G. and De Nardis, L. (2006) Tuning UWB Signals by Pulse Shaping: Towards Context-Aware Wireless Networks. Signal Processing, 86, 2172-2184. http://dx.doi.org/10.1016/j.sigpro.2005.05.037

[34] Bensky, A. (2004) Short-Range Wireless Communication Fundamentals of RF System Design and Application. Elsevier \& Newnes, Amsterdam \& Boston \& Burlington.

[35] Zhang, Y. (2010) RFID and Sensor Networks: Architectures, Protocols, Security, and Integrations. CRC Press, Boca Raton.

[36] Hung, S.Y., Chang, S.I. and Ting, C.P. (2010) Understanding the Key Success Factors of RFID Use in Supply Chain Management: A Delphi Study. International Journal of Mobile Communications, 8, 313. http://dx.doi.org/10.1504/IJMC.2010.032977

[37] Nekoogar, F. (2011) Ultra-Wideband Radio Frequency Identification Systems. Springer, New York.

[38] Zhang, L. and Wang, Z. (2006) Integration of RFID into Wireless Sensor Networks: Architectures, Opportunities and Challenging Problems.

[39] Othman, M.F. and Shazali, K. (2012) Wireless Sensor Network Applications: A Study in Environment Monitoring System. Procedia Engineering, 41, 1204-1210. http://dx.doi.org/10.1016/j.proeng.2012.07.302

[40] Haoui, A., Kavaler, R. and Varaiya, P. (2008) Wireless Magnetic Sensors for Traffic Surveillance. Transportation Research Part C: Emerging Technologies, 16, 294-306. http://dx.doi.org/10.1016/j.trc.2007.10.004

[41] Garcia-Sanchez, A.J., Garcia-Sanchez, F. and Garcia-Haro, J. (2011) Wireless Sensor Network Deployment for Integrating Video-Surveillance and Data-Monitoring in Precision Agriculture over Distributed Crops. Computers and Electronics in Agriculture, 75, 288-303. http://dx.doi.org/10.1016/j.compag.2010.12.005 
[42] Shepherd, R., Beirne, S., Lau, K., Corcoran, B. and Diamond, D. (2007) Monitoring Chemical Plumes in an Environmental Sensing Chamber with a Wireless Chemical Sensor Network. Sensors and Actuators B: Chemical, 121, 142-149. http://dx.doi.org/10.1016/j.snb.2006.09.045

[43] Demirbas, M. (2005) Wireless Sensor Networks for Monitoring of Large Public Buildings. Computer Networks.

[44] Nakajima, N. (2009) Short-Range Wireless Network and Wearable Bio-Sensors for Healthcare Applications. 2009 2nd International Symposium on Applied Sciences in Biomedical and Communication Technologies, Bratislava, 24-27 November 2009, 1-6. http://dx.doi.org/10.1109/ISABEL.2009.5373623

[45] Zeydan, E., Kivanc, D., Comaniciu, C. and Tureli, U. (2012) Energy-Efficient Routing for Correlated Data in Wireless Sensor Networks. Ad Hoc Networks, 10, 962-975. http://dx.doi.org/10.1016/j.adhoc.2011.12.009

[46] Al-Karaki, J.N., Ul-Mustafa, R. and Kamal, A.E. (2009) Data Aggregation and Routing in Wireless Sensor Networks: Optimal and Heuristic Algorithms. Computer Networks, 53, 945-960. http://dx.doi.org/10.1016/j.comnet.2008.12.001

[47] Ha, D. and Schaumont, P. (2007) Replacing Cryptography with Ultra Wideband (UWB) Modulation in Secure RFID. 2007 IEEE International Conference on RFID, Grapevine, 26-28 March 2007, 23-29. http://dx.doi.org/10.1109/RFID.2007.346145

[48] Zhou, Y., Law, C. and Xia, J. (2011) Ultra Low-Power RFID Tag with Precision Localization Using IR-UWB. 2011 IEEE MTT-S International Microwave Symposium, Baltimore, 5-10 June 2011, 1. http://dx.doi.org/10.1109/MWSYM.2011.5973267

[49] Fernandes, J.R. and Wentzloff, D. (2010) Recent Advances in IR-UWB Transceivers : An Overview. 3284-3287.

[50] Granelli, F., Zhang, H., Zhou, X. and Maranò, S. (2006) Research Advances in Cognitive Ultra Wide Band Radio and Their Application to Sensor Networks. Mobile Networks and Applications, 11, 487-499. http://dx.doi.org/10.1007/s11036-006-7195-0

[51] Glisic, S.G. (2007) Advanced Wireless Communications. John Wiley \& Sons, Ltd., Chichester. http://dx.doi.org/10.1002/9780470512883

[52] Li, J., Zhou, B., Sun, Y., Rhee, W. and Wang, Z. (2011) Reconfigurable, Spectrally Efficient, High Data Rate IR-UWB Transmitter Design Using a $\Delta-\Sigma$ PLL Driven ILO and a 7-Tap FIR Filter. Proceedings of 2011 International Symposium on VLSI Design, Automation and Test, Hsinchu, 25-28 April 2011, 1-4. http://dx.doi.org/10.1109/VDAT.2011.5783602

[53] Granelli, F. (2005) Cognitive Ultra Wide Band Radio: A Research Vision and Its Open Challenges. 2nd International Workshop Networking with Ultra Wide Band and Workshop on Ultra Wide Band for Sensor Networks, 2005. Networking with UWB 2005, Rome, 4-6 July 2005, 55-59. http://dx.doi.org/10.1109/NETUWB.2005.1470002

[54] Rashid, R.A., Aripin, N.M., Hamzah, A.E.M., Ahmad, N., Fisal, N. and Yusof, S.K.S. (2008) Cross Layer Design of Cognitive Radio MB-OFDM Systems. 3rd International Conference on Postgraduate Studies (ICPE3), Penang, 2008.

[55] Juengkittikul, P. and Promwong, S. (2009) The Link Budget Evaluation of Ultra Wideband Impulse Radio Transmission Systems. 2009 9th International Symposium on Communications and Information Technology, Icheon, 28-30 September 2009, 474-478. http://dx.doi.org/10.1109/ISCIT.2009.5341201

[56] Promwong, S. (2009) Optimum Template Receiver of Ultra Wideband Transmission Network for Short-Range Wireless Communication Systems. 297-301. http://dl.acm.org/citation.cfm?id=1699392.1699454

[57] Li, Z., Shen, H. and Alsaify, B. (2008) Integrating RFID with Wireless Sensor Networks for Inhabitant, Environment and Health Monitoring. 2008 14th IEEE International Conference on Parallel and Distributed Systems, Melbourne, 810 December 2008, 639-646. http://dx.doi.org/10.1109/ICPADS.2008.66

[58] Zhang, T., Ouyang, Y. and Liu, Y. (2008) Smart Exhibition: Case Study of Integrating RFID with Wireless Sensor Network for Pervasive Computing. 2008 4th International Conference on Wireless Communications, Networking and Mobile Computing, Dalian, 12-14 October 2008, 1-4.

[59] Pereira, D.P., Dias, W.R.A., Braga, M., Barreto, R., Figueiredo, C.M.S. and Brilhante, V. (2008) Model to Integration of RFID into Wireless Sensor Network for Tracking and Monitoring Animals. 2008 11th IEEE International Conference on Computational Science and Engineering, Sao Paulo, 16-18 July 2008, 125-131. http://dx.doi.org/10.1109/CSE.2008.25

[60] Budget, L.L.O.S.L. (2010) Wireless Link Budget Analysis Wireless Link Budget Analysis. How to Calculate Link Budget for Your Wireless Network, 3-6.

[61] Promwong, S., Hachitani, W. and Takada, J.I. (2004) Free Space Link Budget Evaluation of UWB-IR Systems. 2004 International Workshop on Ultra Wideband Systems Joint with Conference on Ultra Wideband Systems and Technologies. Joint UWBST \& IWUWBS 2004, Kyoto, 18-21 May 2004, 312-316.

[62] Irahhauten, Z., Dacu, J., Janssen, G.J.M., Nikookar, H., Yarovoy, A. and Ligthart, L.P. (2008) Analysis and Modeling of Near-Field Effects on the Link Budget for UWB-WPAN Channels. 4872-4876. 
[63] Volos, H.I., Buehrer, R.M. and Anderson, C.R. (2009) A Practical Link Budget for I-UWB Systems. VTC Spring 2009 IEEE 69th Vehicular Technology Conference, Barcelona, 26-29 April 2009, 1-5. http://dx.doi.org/10.1109/VETECS.2009.5073331

[64] Liu, L., Dong, X., Tian, Z. and Schwartz, A.L. (2009) Link Budget Analysis and Throughput Measurement for MultiAntennas WiMedia UWB Systems. 2009 IEEE 70th Vehicular Technology Conference Fall, Anchorage, 20-23 September 2009, 1-5.

[65] Promwong, S., Hachitani, W. and Takada, J.-i. (2004) Free Space Link Budget Evaluation of UWB-IR Systems. 2004 International Workshop on Ultra Wideband Systems, 2004. Joint with Conference on Ultrawideband Systems and Technologies. Joint UWBST \& IWUWBS, 18-21 May 2004, 312-316

[66] Ramesh, C. and Vaidehi, V. (2007) Performance Analysis of UWB Channels for Wireless Personal Area Networks. Wireless Personal Communications, 41, 169-178. http://dx.doi.org/10.1007/s11277-006-9136-4

[67] Gigl, T., Troesch, F., Preishuber-Pfluegl, J. and Witrisal, K. (2010) Maximal Operating Distance Estimation for Ranging in IEEE 802.15.4a Ultra Wideband. 2010 7th Workshop on Positioning, Navigation and Communication, Dresden, 11-12 March 2010, 10-18.

[68] Oh, M.K., Park, J.H. and Kim, J.Y. (2009) IR-UWB Packet-Based Precise Ranging System for u-Home Networks. IEEE Transactions on Consumer Electronics, 55, 119-125.

[69] Le Boudec, J.Y. and Merz, R. (2008) Interference Management in Impulse-Radio Ultra-Wide Band Networks. EPFL (Lausanne).

[70] Mendes, L.D.P. and Rodrigues, J.J.P.C. (2011) A Survey on Cross-Layer Solutions for Wireless Sensor Networks. Journal of Network and Computer Applications, 34, 523-534. http://dx.doi.org/10.1016/j.jnca.2010.11.009

[71] El-Fawal, A., Le Boudec, J.Y., Merz, R., Radunovic, B., Widmer, J. and Maggio, G.M. (2005) Tradeoff Analysis of PHY Aware MAC in Low-Rate, Low-Power UWB Networks.

[72] Perez-Guirao, M.D., Lubben, R., Zhao, Z., Kaiser, T. and Jobmann, K. (2007) Cross-Layer MAC Design for IR-UWB Networks. 2007 International Workshop on Cross Layer Design, Jinan, 20-21 September 2007, 113-116. http://dx.doi.org/10.1109/IWCLD.2007.4379050

[73] Wang, T. (2011) Cross-Layer Design and Optimization of Short Range Wireless Networks. Ph.D. Thesis, Department of Electrical and Computer Engineering, University of Rochester, Rochester.

[74] Wu, S.H., Zhang, Q.L., Zhang, Q.Y.and Yao, H.P. (2011) Integrative Ranging and Positioning for IR-UWB Wireless Sensor Networks. Proceedings of the 2011 Third International Conference on Communications and Mobile Computing (CMC '11). IEEE Computer Society, Washington DC, 489-494

[75] Fabeck, G., Bielefeld, D. and Mathar, R. (2008) Cross-Layer Design of IR-UWB Sensor Networks for Distributed Detection Applications. IEEE International Symposium on Wireless Communication Systems, ISWCS 08, Reykjavik, 2124 October 2008, 603-607.

[76] Tan, K., Wu, D., Chan, A. and Mohapatra, P. (2011) Comparing Simulation Tools and Experimental Testbeds for Wireless Mesh Networks. Pervasive and Mobile Computing, 7, 434-448. http://dx.doi.org/10.1016/j.pmcj.2011.04.004

[77] Xiao, Z.Y., Ge, N. Pei, Y.K. and Jin, D.P. (2011) SC-UWB: A Low-Complexity UWB Technology for Portable Devices. 2011 IEEE International Conference on Signal Processing, Communications and Computing (ICSPCC), Xi'an, 14-16 September 2011, 1-6.

[78] Mallat, A., Gerard, P., Drouguet, M., Keshmiri, F., Oestges, C., Craeye, C., Flandre, D. and Vandendorpe, L. (2010) Testbed for IR-UWB Based Ranging and Positioning: Experimental Performance and Comparison to CRLBs. 2010 5th IEEE International Symposium on Wireless Pervasive Computing (ISWPC), Modena, 5-7 May 2010, 163-168.

[79] Feldman, A., Bahr, A., Colli-Vignarelli, J., Robert, S., Dehollaini, C. and Martinoli, A. (2011) Toward the Deployment of an Ultra-Wideband Localization Test Bed. 2011 IEEE Vehicular Technology Conference (VTC Fall), San Francisco, 5-8 September 2011, 1-5.

[80] Irahhauten, Z., Dacuna, J., Janssen, G.J.M., Nikookar, H., Yarovoy, AG., Ligthart, L.P. (2008) Link Budget Analysis and Modeling of Short-Range UWB Channels. IEEE Transactions on Antennas and Propagation, 56, 2730-2738.

[81] Volos, H.I., Buehrer, R.M. and Anderson, C.R. (2009) A Practical Link Budget for I-UWB Systems. Vehicular Technology Conference, 2009. VTC Spring 2009. IEEE 69 ${ }^{\text {th }}$, 26-2 April 20099, 1-5.

[82] Promwong, S. (2009) Waveform Distortion Analysis on Transmission Gain and Group Delay of Ultra Wideband Impulse Radio. International Symposium on Intelligent Signal Processing and Communications Systems, 2008. ISPACS 2008, 1-4.

[83] Liu; L.B., Dong, X.D., Tian, Z.Z. and Schwartz, A.L. (2009) Link Budget Analysis and Throughput Measurement for Multi-Antennas WiMedia UWB Systems. Vehicular Technology Conference Fall (VTC 2009-Fall), 2009 IEEE 70 th, 
1-5.

[84] Lecointre, A., Dragomirescu, D. and Plana, R. ((2009) Design and Hardware Implementation of a Reconfigurable Mostly Digital IR-UWB Radio. Romanian Journal of Information Science and Technology (ROMJIST), 11, 295-318.

[85] Lecointre, A., Dragomirescu, D. and Plana, R. (2007) Study of Reconfigurable Mostly Digital Radio for MANET. Semiconductor Conference, 2007. CAS 2007. International, 1, 237-240.

[86] Lecointre, A., Dragomirescu, D. and Plana, R. (2010) Largely Reconfigurable Impulse Radio UWB Transceiver. Electronics Letters, 46, 453-455.

[87] Xia, L., Huang, Y. and Hong, Z. (2008) Low Power Amplitude and Spectrum Tunable IR-UWB Transmitter. Electronics Letters, 44, 1200-1201,.

[88] Li, J., Zhou, B., Sun, Y.F., Rhee, W. and Wang, Z.H. (2011) Reconfigurable, Spectrally Efficient, High Data Rate IR-UWB Transmitter Design Using a $\Delta-\Sigma$ PLL Driven ILO and a 7-tap FIR Filter. 2011 International Symposium on VLSI Design, Automation and Test (VLSI-DAT), 1-4.

[89] Verhelst, M., Ryckaert, J., Vanderperren, Y. and Dehaene, W. (2008) A Low Power, Reconfigurable IR-UWB System. IEEE International Conference on Communications, 2008. ICC '08, 3770-3774. 
Scientific Research Publishing (SCIRP) is one of the largest Open Access journal publishers. It is currently publishing more than 200 open access, online, peer-reviewed journals covering a wide range of academic disciplines. SCIRP serves the worldwide academic communities and contributes to the progress and application of science with its publication.

Other selected journals from SCIRP are listed as below. Submit your manuscript to us via either submit@scirp.org or Online Submission Portal.
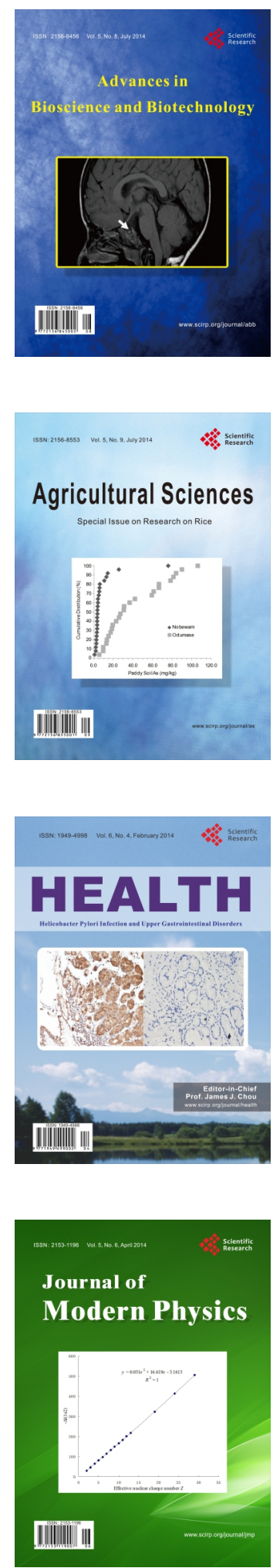
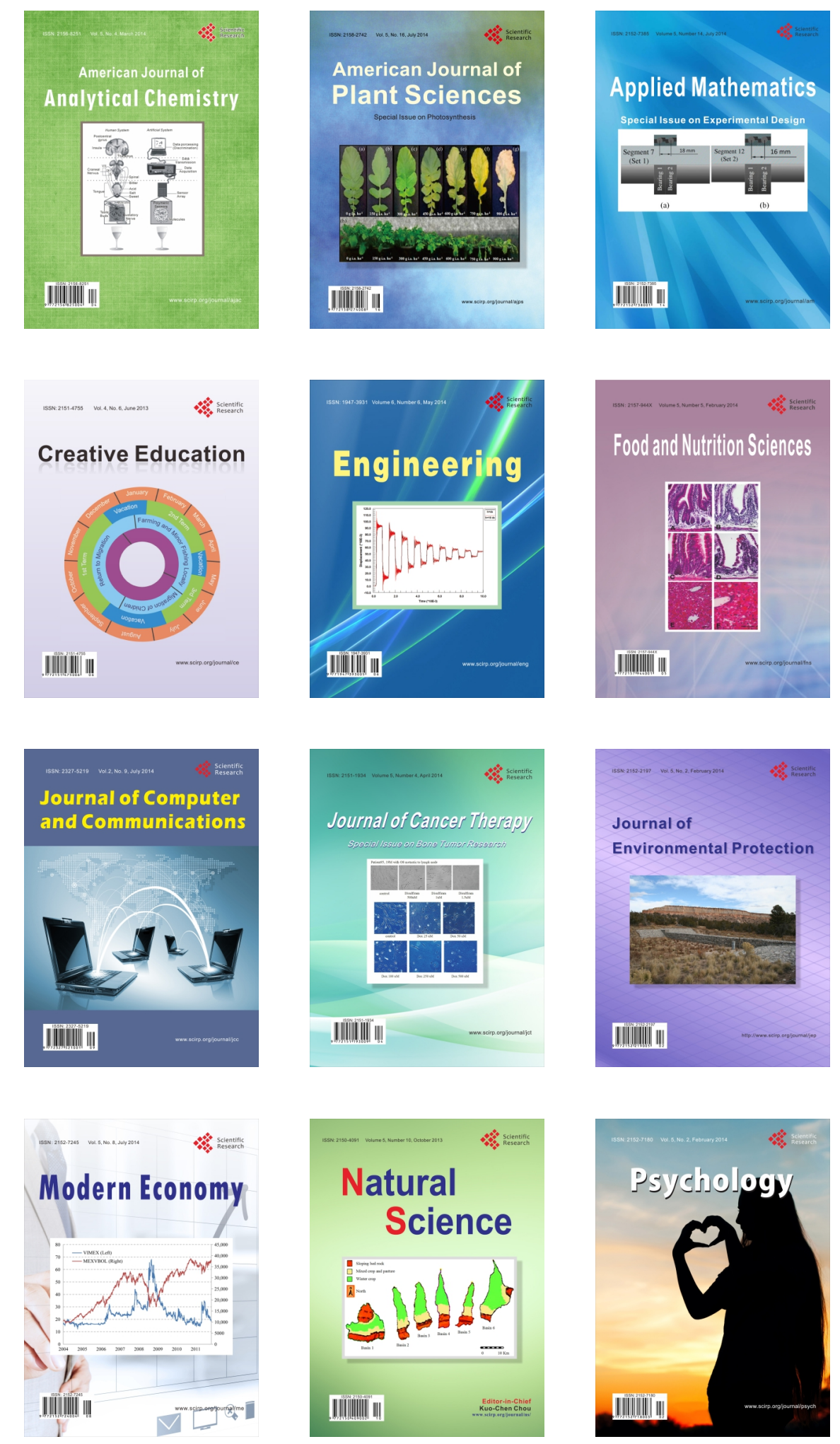